\title{
Manifestations of Service Culture among Street Vendors in Botswana
}

\author{
Byron A. Brown ${ }^{1} \&$ Ms Goaletsa Rammidi ${ }^{1}$ \\ ${ }^{1}$ Botswana Accountancy College \& University of Derby in Botswana, Botswana \\ ${ }^{2}$ Faculty of Computing and Information Technology, Botswana Accountancy College \& University of \\ Sunderland in Botswana, Botswana \\ Correspondence: Byron A Brown, Botswana Accountancy College \& University of Derby in Botswana, \\ Botswana. E-mail: byronb@bac.ac.bw
}

Received: April 29, 2014

Accepted: July 17, 2014

Online Published: August 22, 2014

doi:10.5539/ijbm.v9n9p244

URL: http://dx.doi.org/10.5539/ijbm.v9n9p244

\begin{abstract}
In the non-western developing world, where the majority of the world's street vendors can be found, service culture is under-researched. For instance, although street vendors are entrepreneurers, it is not always clear how or to what extent they value customers. Nor is it self-evident what kinds of service culture prevail in street vendors' business, or how such culture supports service improvement. Using a qualitative approach, involving a sample of 30 street vendors who were interviewed and observed, this research described the basic characteristics of the service culture practices and values among street vendors in micro-enterprises. The study found that unique service cultures prevail among street vendors, ranging from humane clues evidenced in practices and values in encounters with customers and interaction with each other, to mechanic clues evidenced in the orchestration of their physical environment. A major contribution of this study is in showing that understanding the characteristics of the service culture in terms of practices and values provides useful insights for service quality improvement in street vending. The study made various recommendations for informal sector development.
\end{abstract}

Keywords: street vending, service culture, service encounters, Botswana

\section{Introduction}

In the non-western developing world, where the majority of the world's street vendors can be found, service delivery culture is under-researched. For instance, a search for studies on street vendor service culture in developing country results in two papers, one by DR1 (2007) and another by Brown and Rammidi (2012). Although street vendors are entrepreneurers, it is not always clear from any of these studies as to how vendors value customers, or sustain good relationships with them. Nor is it self-evident from any of the research done what kinds of service culture prevail in street vendor enterprises.

Historically, though, street vending has been couched in an informal socialisation and has been characterized largely by a product culture - with no meaningful attention to service delivery (Muiruri, 2010; Renaut, 2004). In many developing countries, street vending is associated with customer harassment, physical assault, crime, security risks, health and environmental problems (Jimu, 2004; Muiruri, 2010; DR1, 2007). The association of street vending with aggression and confrontation give the impression that street vending is not a place where customers can expect high quality service experience.

However, with the growing importance of street vending as an economic activity in many developing nations globally, street vendor service delivery practices need close monitoring - much the way it is emphasized in the formal business sector (Davis, Gautam \& Bhat, 2012; Gronroos, 2007). Empirical studies lend support to the notion that service delivery quality is inherently linked to the service culture that dominates the business (Schneider \& Bowen, 2009; Davis, Gautam \& Bhat, 2012; Gronroos, 2007). This claim may be true for informal enterprise as much as it may be for formal business endeavours. Furthermore, street vending is a growing business in many developing countries. In Botswana, for example, street vending and other forms of informal sector development activities are being encouraged to promote self-reliance. In other words, street vending is being legitimised and encouraged as a strategy to boost socio-economic development and transformation in communities where poverty and unemployment exist, and where a need exists to promote social justice in terms of gender and other variables (Jima, 2004; ILO, 2002; Muiruri, 2010). Forecasts of street vending activities project growth in the market segment served by street vendors in African countries such as Botswana (CSO, 
2011). Clearly, street trading is growing in its profile and significance and the quality of the services delivered by street vendors need to do likewise.

If street trading is to remain a viable sector with a sustainable future, street vendors will need to be more responsive to customer service priorities. It will also need to take more initiative to deliver high quality services in a consistent way, and make a shift from a product to a service cultural orientation. The service culture may hold the key to a better understanding of ways to influence the quality of service delivery in street vending (Gronroos, 2007). Through improvement in service culture, street vendors may be able to promote a positive public perception of their business, certainly in Botswana. Policy support for street enterprise may be enhanced through the framing of a better understanding of service culture characteristics among street vendors. Informal business development policies of economic development agencies in many developing countries (e.g., Citizen Entrepreneurial Development Agency in Botswana) (Letebele, 2012) may be strengthened to include technical advice that focuses on informal business management support in terms of leveraging service culture to create value for the business and to drive a service mindset.

Thus, although service culture is pivotal in street vending enterprise, it is not self-evident as to the kinds of service culture that prevails in street vendor business, or how insights into such service culture may create the necessary awareness for change to deliver better service. This research describes the basic characteristics of the service culture practices and values among street vendors in enterprises. A major contribution of the study is showing that understanding the characteristics of the service culture in street vending provides useful insights for service quality improvement in street enterprises.

The paper begins with an overview of street vending, services, and culture. The whole question of the nature of street vending is discussed, along with the notion of service and business culture. Influences on business culture are discussed, followed by the methods that framed for the investigation. The paper rounds off with the results and conclusion.

\section{Literature Review}

\subsection{Service Culture and Street Vending}

The term 'service culture' requires a discussion of both the concept 'service' and 'culture'. The term service is much less contested than culture. Service is generally understood as actions taken to create intangible and insubstantial value for customers (Gronroos, 2007). This implies that after customers have been assisted either by a self-service or full-service process, they feel better off than before. Thus, the value in service is linked to customer satisfaction (Vargo \& Lusch, 2008). On the other hand, 'culture', as a concept, has been theorised by both Schein (2009) and Hofstede (Hofstede \& Hofstede, 2005). To Hofstede and Hofstede (2005), culture is a group's mental programming. Alternatively, to Schein (2009) and others (see Hofstede, 1984; Martin, 2002), culture is the integrated pattern of learned behaviours of a group, evidenced through shared ceremonies, thoughts, languages, knowledge, beliefs and values. Both require learning, which gets developed overtime as the group deals with its own internal integration and survival problems (Schein, 2009). Schein's view of culture guides this study as it has greater relevance to street vending because of its emphasis on social learning as a mechanism to transmit culture (Bandura, 1986).

One of the lessons we can extract from the definitions of 'culture' is that street enterprise as a whole constitutes a business culture because as a collective force, street vending has distinct membership. Street vending is understood as an 'illegal' working entity, characterised by roadside or sidewalk location, with self-made stalls or tents, mobile carts, or open air display of merchandises (Muiruri, 2010). This collective scenery gives street vending uniqueness. Secondly, the everyday vending practices that reflect "how vendors do things around here" (Deal \& Kennedy, 2000:1) affirms street vending as culture. The latter is important because the everyday micro level vending practices provides the most powerful expression of culture. These perspectives about street vending, as culture, have guided the way governments view street vending (see Muiruri, 2010; ILO 2002; Jimu, 2004).

Although street trading is steeply product based, vendors do provide services alongside the products that they trade. For many street vendors, service delivery constitutes only part of their overall business activities. Several studies support this observation. Boseo, Lee, Olson and Severt (2011) revealed that out of eight street food vendors (meal product) they investigated in the USA, five had some form of "host" who directed guests throughout their experience (service). The most commonly reported services provided by these street food vendors were attention to ambience, the setting and clearing of the tables, and the etiquette of meal serving (Boseo et al, 2011). 
Likewise, vendors of perishable goods in North America offer services that range from attention to vendors' own personal hygiene to the handling, storage and display of their fruits and vegetables (Bonnin, 2006). In many African countries, street vendors provide services in the form of considered assistance and support (Muiruri, 2010). But it may not be the case that all street vendors show regard to the delivery of service (or quality service) Walsh (2010) found that in parts of Vietnam, and the Greater Mekong Sub-Region, most work in the informal sector offers little in the way of value-added activities. DR1 (2007) maintains that in Dominica some street vendors are more hard pressed with concerns about their survival than with the delight of customers. While the normative services that a street vendor provides may be influenced by the nature of the vending business, these contrasting case studies suggest that there may be a driving force underlying how customers are offered services.

Clearly, then, in street vending, service culture is an atmosphere, comprising both intangible and tangible actions of service, aimed to create value for customers (Bowen, Schneider \& Kim, 2000). It is reflected in shared customs, knowledge, values, beliefs and assumptions.

\subsection{Manifestations of Service Culture}

\section{- $\quad$ Discernible aspects of service culture: Service cultural practices}

Schein (2009) argues that [service] culture variables exist at three levels, namely: artefact and behaviour, espoused value, and basic assumptions. Alternatively, Hofstede and Hofstede (2005) maintain that culture manifestation at two different levels of depth, namely practices (i.e., symbols, heroes, and rituals) and core values. Both Schein and Hofstede and Hofstede views are similar. Symbols represent cultural practices, expressed through words, pictures, gestures and objects, which carry meaning. Whereas heroes are individuals, with characteristics valued in the culture, rituals represent collective activities in which cultural group engages (Hofstede \& Hofstede, 2005). The way we greet or pay respect to others is an expression of rituals. These correspond to artefacts and behaviours, which are discernible aspects of service culture because they are audible and observable patterns of a group (Schein, 2009).

In business, cultural practices may be demonstrated in various forms, including through observable policies (regarding giving good services to customers), procedures and behavioural norms during service encounters (Hoang, Hill \& Lu, 2010; Ostrom et al, 2010). It may also be demonstrated through the elements of the service environment (Boseo et al, 2011), and through individual level factors such as the personal characteristics of service providers (Schein, 2001; Vella, Gountas \& Walker, 2009). Each of these has been area of focus in previous research.

In a service situation, service practices start unfolding the moment service providers and recipients are drawn into an encounter. Price, Arnould and Tierney (1995) refer to this encounter as 'the moment of truth'. Both discernible and indiscernible elements of service culture converge. In service relationship, service culture practices may be evident in three areas: the service duration, affective content, and spatial proximity (Price et al, 1995). Previous research found that time spent in service encounter impacts on service practices. Service culture in which there is extended duration (more than few minutes) in the service encounter results in service transactions that resemble relationship between friends, compared to the brief duration in which the transaction is business specific (Noone Kimes, Mattila, \& Wirtz, 2009; Price et al, 1995; Mohr \& Bitner, 1991). Price at al (1995) demonstrated that extended service encounter duration results in shared feelings of intimacy, empathy, and self-revelation. But it has the disadvantage of developing into a service culture in which there is frequent errors and obstacles from environmental and inter- and intrapersonal sources (Siehl, Bowen \& Pearson, 1992). Thus, time in the encounter may be a marker of service culture practice.

Another variable of service culture practice is the affective content of service delivery. 'Affective content', Price et al (1995) maintain, is the emotional arousals inherent in service encounters. In street vending, emotional content may exist in varied ways in service practices. But the nature of this content depends on whether the encounter is high- or low- affect context. Siehl et al (1992) suggest high-affect contexts are produced in extended encounter duration. Service encounters characterised by high-affect context provide customers with not just functional benefits (e.g., easy access to inexpensive goods) but also affective benefits (e.g., chats, laughter, and stories shared in the encounter) (Price et al, 1995; Noone et al, 2009). A service culture devoid of high-affect encounters exhibits practices that are low in functional or affective benefits. Thus, what gets talked about, how it is talked about, and the vending location contribute to the quality of the affective aspect of service culture.

The encounter between service provider and recipient may be remote, relatively near (e.g., separated by a stall), or intimate (e.g., in direct contact). Proximity between service provider and customer contributes to the nature of the service culture that develops (Noone et al, 2009; Siehl et al, 1992). When people are spatially close, they develop feelings of attachment (Kitayama, 2002). Most street enterprises are loosely coupled entities, operated 
by a single vendor, with family member assistance, but the spatial network distance between vending stalls, especially in urban areas in developing countries, is sometimes so close, almost zero (Muiruri, 2010). In Botswana, many street enterprises are found at the bus and train stations in the city and towns. The network distance between any two vending service points in Botswana varies from less than one-half meter in the Central Business District to three meters in the suburban and peri-urban areas, or further apart in rural areas. Close proximity may permit diffusion of service culture by virtue of vendors' interactions and social learning through observation and modelling (Klein \& Kozlowski, 2000).

\section{- Indiscernible aspects of culture: Cultural values and assumptions}

Cultural values and basic assumptions are less discernible than artefacts/behaviours. Both behaviours and core values are shaped by our basic assumptions (Schein, 2009). However, as standard of behaviours, cultural values can be inferred from behavioural norms. Salzmann (2007) maintains that in many businesses, employee conduct is guided by beliefs related to enthusiasm, interest in customers, flexibility, and relationship (anticipation, connection; liveliness; knowledgeability). Lytle, Hom and Mokwa (1998) studied cultural values as they relate to 'giving good services' and found empathy as a key value. Poulin (2010) proposes nine core cultural values, which he argues contribute to service culture development. These include truth telling, promise-keeping, respect, loyalty, discipline, empowerment, flexibility, quality assurance, and results. Clearly, service culture values may vary from context to context but where shared meanings manifest, they create communities out of individuals. This suggests that although street vendors operate as isolated business entities, they may be 'glued' together as a community by cultural value they share in service delivery.

National culture may penetrate business culture (Salzmann, 2007; Schein, 2001), and this is true of street vending. In the African context, national cultural values such as 'botho', 'ubuntu', collectivism, masculinity, and cooperation may influence service culture practices among street vendors. This penetration may be possible because cultural values are transmissible and are carried by people. A vendor, who observes customer loyalty resulting from trust between a neighbouring vendor and her customers, may be motivated to adopt similar service value. The modelling of values from the individual to the group equates to a bottom-up process (as opposed to top-down process) of culture development (Klein \& Kozlowski, 2000).

Furthermore, basic assumptions represent the deepest level of service culture (Schein, 2009). Basic assumptions are intangible and cannot be observed directly, but can be merely inferred from our actions (Inglehart \& Bake, 2000). Inference may be drawn not just from patterns of communication but also from the way information is processed and communicated, and use of physical space. BCL (2013) isolates three basic assumptions that govern everyday business transactions, including street vending transactions. One of these assumptions is that human nature is essentially good vs. human nature is essentially evil; another is that people are born equal vs. people are born unequal. The final one is that the world is governed by rational laws vs. the world is governed by arbitrary laws. Hofstede and Hofstede (2005) add another basic assumption to those mentioned by BCL. Hofstede and Hofstede maintain that in national culture, a basic assumption is that individuals are supposed to take care of themselves and their immediate families only and in-group is suppose to take care of its members. The basic assumptions in street vendors' service culture may be anchored in their national culture (BCL, 2013).

In a service encounter guided by the assumption that human nature is essentially good, there will be a high level of 'trust' (as opposed to distrust) in service encounter relationships (BCL, 2013). Furthermore, in African societies, national culture is grounded in collectivism culture (as opposed to individualism) (Hofstede \& Hofstede, 2005). In contrast to individualist cultures, collectivist cultures tend to be high-context in its communication style and holds expectations of group protection. Thus, in communication, the message is often 'vague, indirect, and implicit'. Loyalty is given in return for protection. The assumption of care and protection suggests any violation of the expectation associated with collectivism norms may lead to miscommunication and distrust during service encounters.

Botswana culture offers a case in point. There are several ways in which Batswana (people of Botswana) traditionally react in service delivery interaction. According to Batswana customs, service delivery begins from as early as the customer draws near to the business establishment and carries on until the customer departs. The whole encounter process is expected to be intertwined with a display of humane characteristics: make eye contact, relax face muscles, acknowledgement of customer(s) from a distant, and possibly conversation unrelated to business. In all of this, the nature of the service provider-customer interaction is expected to be unhurried, with courtesy or norms of behaviours exhibited throughout encounter.

\subsection{Street Vending in Botswana}

Aside from the cultural issues, Botswana has made considerable economic progress, which has earned the 
country acclaim as one of the leading African economic success stories. Despite this, there are just not enough jobs for everyone seeking formal employment in Botswana. Unemployment and its related outcomes such as poverty remain a challenge in rural and urban areas in the country (Brown, 2005). In 1991, it was estimated that 21 percent of families in Gaborone were below the poverty datum line (PDL) compared to 55 percent national average (Hope, 1997, p. 24). One special aspect, though not unique to Botswana, is that many citizens have turned to the informal sector, and street vending in particular, as a means to earn a living and mitigate poverty.

Street vendors are the most conspicuous informal economic actors in major cities and towns in Botswana. A cursory survey shows street vendors are located along the roadways, in and around shopping malls, supermarkets, industrial escarpments, in the vicinity of car parks, bus and train stations, and by the wayside of residential premises. Many can also be found in strategic location in rural communities. These people are not philanthropists, but rather are serious entrepreneurers trading one thing or another, ranging from the perishable (e.g., juices, cooked meals, sweets, fruits and vegetables) to the non-perishable (e.g., music discs, clothes and shoes, cell phone chargers and repairs, airtime cards and mobile phone services). Many of the goods and services they trade could be accessed from nearby retail outlets but street vendors provide added competition due to their accessibility and affordability. Furthermore, although many street vendors in Botswana are self-employed and are the sole-owner of their enterprise, an emerging reality is that formal retail businesses have joined the sector by using their staff to trade items on the street. In a study of urban informal sector profiles, linkages and constraints in Francistown, Butale (2001) acknowledged the existence of street vending, but hinted that much of street vending was a spill over of non-street formal production and distribution of goods.

Street vending has a central role to play in the socio-economic development of Botswana, in so far as self employment and the minimization of social problems associated with unemployment are concerned. It has been acknowledged that street vendors, and actors in the informal sector in general, are crucial to the development of the economy and the attainment of the long-term vision of Botswana, the Vision 2016, which envisions a Botswana which is prosperous and hospitable (Presidential Task Force, 1997). Local authorities continually embark on zoning of areas for vendors and many vendors have conformed to these requests to trade in designated areas. But many urban leaders and planning agencies tend to be compassionate towards street vendors even when they set up business in undesignated areas. Thus, though urban planning agencies still tend to look upon the vendors as an impediment to the designed development of cities and towns, street clearing exercises, destroying stalls and confiscating supplies are less commonplace. This atmosphere allows street enterprise to flourish.

In sum, street vending is a service linked to socio-economic goals. Service is clearly embedded in culture. It can be deduced from the foregone analysis that service culture may manifest at different levels, ranging from overt practices to the intangible ones. Several forces may influence how service cultures manifest, many stemming from broad national culture factors to individual level characteristics such as attitudes (Salzmann, 2007; Erez \& Gati, 2004; ). The nature of the service context also plays a role (Johansson, 2013). In the African context, there has been little attempt to explore the service culture among street vendors and how this manifests in practices. Botswana is one African country where street vending enterprise is growing (CSO, 2011; Jimu, 2004). The country was chosen as a case to explore the following key issues: (a) The basic characteristics of the service culture practices and values among vendors in street enterprises; and (b) The implications of the service culture for service quality enhancement in the informal business context.

\section{Theoretical Framework and Methodology}

This study is informed by two theoretical perspectives. First, the resource-based view of enterprise (Yang, 2008). The resource-based view looks at service culture as a resource and considers service culture as a valuable and unique characteristic that can give a business some advantages over its rival (Yang, 2008). In other words, it holds that as the quality of services leads to better outcomes, and as the need to survive in a fiercely competitive business environment becomes more and more a priority, service culture becomes a valuable resource. As a fiercely competitive business (DR1, 2007), street vending activities lend themselves well to the resource-based perspectives. Street vendors' stories can provide insights into their perspectives about service culture as a resource, and how such a resource can sustain their business, including its use to encourage themselves to go the extra mile to serve customers.

Service culture may develop from either a micro or macro level. Thus, Klein and Kozlowski's (2000) multi-level theory of culture also inform this study. It argues that service culture develops, either through top-down processes (macro) or bottom-up processes (micro). Bottom-up processes begin at the individual level, and through dynamic interactions and social learning, the transfer of culture occurs and gains stable properties over 
time. By contrast, the top-down process of culture development occurs through high-level societal or institutional level changes. The bottom-up process is most pertinent in this study as it can help with understanding how service culture emerges from individual street vendors into a group cultural characteristic. The resource based perspectives and the multi-level theory have inherent qualities that make them well suited to provide explanations to the research problem expressed in this paper.

\section{Methodology}

Given that the aim was to understand manifestations of service culture among street vendors, a qualitative approach was adopted. This approach lends itself well to the interpersonal interaction required to access service culture issues. The sources of information for this study were personal interviews and participant observation. Use was made of semi-structured interviews, accomplished through face-to-face meetings with the street vendors For these reasons, the study was exploratory. Street vendors in the city and towns within the Greater Gaborone areas of Botswana (the main municipality) were used as participants because these vendors provide a good expression of the vending cultural mix in general. The Greater Gaborone area includes six divisions. In order to spread the sample population over a wide area of the municipality, the area was sub-divided into six zones: Gaborone City Centre (main mall market area), Gaborone Railway Station, Gaborone Bus Station, BBS Market area, Mogoditshane Choppies/Spar area (Molepolole road), and Gabane town Bus Rank. Purposive sampling in each zone allowed a typical cohort of street vendors, with a good understanding of the topic of the study, to participate.

\subsection{Sample}

The key to sample selection is an updated list of the target population. The Central Statistics Office (CSO) in Botswana estimates that about 7,000 informal business enterprises operated in the Greater Gaborone area of Botswana in 2011 (CSO, 2012). About 2500 of these are street vendors. Given that the study was designed within an interpretivist paradigm, where the focus was to understand the meaning of participants' responses, 30 street vendors (comprising 25 females and 5 males) were purposively selected as sample. The main sampling criterion was trading on the street, stall type, and years trading on the street, regardless of the merchandise type. On average, the vendors were involved in street trading for about 5 years. The majority (53.3\%) of the vendors operated from temporary stalls, while others (17\%) operated from portable devices (e.g., vehicles; mobile cart) and still others (29.7\%) from permanent stalls/kiosk. Most of the vendors (63.3\%) traded non-perishable goods.

\subsection{Instrument and Procedure}

Two different methods were used to collect data, namely face-to-face interview and participant observation. The semi-structured approach was adopted in order to keep a degree of consistency in the questions that respondents were asked, and a degree of flexibility in the interview exercise to have respondents relate their stories. During initial meetings with the street vendors, the exact nature of the study was explained to them and a date and time set for the interview. The interviews were conducted at the home of street vendors, on their recommendation. Interviews were conducted using the Setswana version of the Street Vendor Culture Interview Guide (SVCIG), developed by the researchers after consulting the literature and similar instruments.

To familiarise themselves with the themes of the interview, the participants were given the SVCIG a week before the face-to-face conversation. Being semi-structured, the interview guide covered a range of themes such as vendor demographic characteristics; service culture practices and norms; service culture values and assumptions; influences that led to the particular service culture; and views of service culture as a resource. Probe questions were used if initial responses were uninformative. The key to improve the credibility of the interview data is being able to interact with the verbatim of participants. Thus, interviews were mechanically recorded with participants' permission.

In addition, participant observation was used to understand the behavioural and attitudinal aspects of service culture during the vendor-customer service encounters. Attitudinal, verbal and non-verbal service behaviours were observed. One research assistant was posted per vending site to make observations. Although the participants were informed about the observations, they were unaware of the person assigned to make the observations. Observing discreetly minimized interference in the natural street vending settings, thereby ensuring the process was naturalistic. The data sources improved the credibility of the study.

Qualitative data treatment techniques including thematic content analysis, which involved coding and categorising the data to make sense of its meaning, were used to analyse and interpret the results. Descriptive statistical techniques such as frequencies and percentages were used to summarise the demographic data. Low inference descriptors were used as themes in the analysis, which along with the multiple data sources and peer 
review, contributed to improve the trustworthiness of the data. Two major shortcomings impinged on the information collected from the vendors. First, their apparent lack of trust as demonstrated in their initial unwillingness to talk freely to the researchers; they held the view that the researchers were agents of the state who came to persecute them; and, second, their general expectation of a reward to participate and share their information. While this made it difficult to gain their cooperation and to share their time, their non-withdrawal after being informed that issuing reward violates the research ethics implies that they understood and voluntarily participated.

\section{Findings}

Several issues emerged consistently from the stories shared in the interviews. Most notably: (a) the participants acknowledged being providers of services to their customers, and recognised the importance of, and held strong belief in, treating customers as a priority; (b) all acknowledged having their approach to serving customers; (c) for many, service meant 'customer satisfaction, helping, non-discrimination-providing service to each customer in the same way'. The street vendors felt a sense of importance in what they do. For instance, many talked of the joy, enthusiasm and sense of self-reliance, as well as the need to survive-as features of their experience and the reasons they were involved in street enterprise. These sentiments emerged as themes in the service encounter interactions.

\subsection{Practices and Values in the Service Encounter Interactions}

Valuing customer: It was apparent from the interviews and the subsequent participant observations that street vendors valued their customers. The appreciation was expressed in various ways, one of which was the customer 'priority treatment'. But street vendors also valued their street enterprise. The service delivered to customers was greatly influenced by the way in which street vendors felt about their business and clients. This point was well captured in the views of one participant:

I am motivated [to work hard] by factors of life because when you are self-employed you expect a lot from the business; that you can be able to help yourself, your kids and your parents... I tell myself that I want to help myself so that I can be able to provide for my needs... as a result, I have to give attention to my customers because without them, I don't have a business; and without this business, I have nothing...this is how I survive; and others are depending on me [Mpho].

Even as street vendors pursued success in their business, they did not become disconnected from their customers. They clearly did not treat their customers with ambivalence, or took them for granted. A feature of the treatment of customers was valued empathy. This treatment of customers, and the acknowledgement of their central role in the survival of their business, appeared to help street vendors stay in-tune with the service needs and experiences of their clients. Previous research in the formal business setting supports the customer first approach adopted by street vendors (Russell, 2012; Noone Kimes, Mattila, \& Wirtz, 2009). Noone et al (2009) assert that a fundamental success factor in business is to treat customers with respect and put them first. Russell (2012:1) concluded from his work among SMMEs that, “...to feel served, customers require undivided attention and focus'. The street vendors appeared to clearly understand these requirements. The sentiment was evident among vendors, regardless of the nature of the merchandise they traded.

One of the obvious benefits of valuing customers in a business is that it reduces the chances to be rude, careless or to take a long time to assist them. Competition can be fierce among street vendors, especially among street entrepreneurs in city areas (DR1, 2007). In an environment where a customer is able to easily turn to a different service provider, there is very little margin for errors in the way customers are treated. Street vendors cannot afford to be rude, careless or to take a long time to deliver service to clients. The investment of time and attention to customers as norm is acknowledgement of the need to 'survive' in the business as vendors.

Investing time in service encounter relationships: At the heart of a service is the encounter, i.e., the point of interface and interaction between the server and the served. The duration of this encounter is one of the many elements in the relationship. The contents of the interaction and the proximity of the parties in the interaction make up the other elements (Price, Arnould \& Tierney, 1995). For street vendors in this study, location, i.e., doing business within or outside the city had an influence on service encounter duration. Service encounters were most frequent among street vendors in the city centre (i.e., Central Business District, Main Mall Shopping area, Railway and Bus Stations). This is understandable as the city had the highest population density, and was the wealthiest urban centre, with direct links by road and rail networks to other economically important towns in the country and the South Africa Development Region.

The rate of service encounters declined sharply with distance from the city centre. As distance increased from 
the city centre, street vendors in this study noticeably spent much more time in interaction with each customer. Table 2 shows the location of the street vending businesses, the relative distance between locations, and the average time-which ranges from 1.15 minutes to 1.75 minutes-that vendors spent in encounters with customers $(\mathrm{r}=0.9517, \mathrm{p}=0003)$.

Table 2. Locations of street vendors by average time spent with customers

\begin{tabular}{lll}
\hline Location of street vending business (study area) & $\begin{array}{l}\text { Distance from city centre } \\
(\mathbf{k m})\end{array}$ & $\begin{array}{l}\text { Average time spent with customers } \\
(\mathbf{m i n s})\end{array}$ \\
\hline $\begin{array}{l}\text { City Centre (i.e., Gaborone Main Mall; Railway and Bus } \\
\text { Stations) }\end{array}$ & 0 & 1.15 \\
BBS Market area & 5 & 1.23 \\
Mogoditshane Choppies/Spar area (Molepolole road) & 8 & 1.28 \\
Gabane town Bus Rank area & 25 & 1.75 \\
\hline
\end{tabular}

Note: $\mathrm{r}=0.9517, \mathrm{p}=0002$.

The correlation between the distance and the average time duration shows a strong positive linear relationship, which is statistically significant at the one percent level of significance, with three degrees of freedom. Compared to those located outside the city centre, street vendors located in the urban centre had relatively brief encounters with customers. This was largely a result of the number of customers on hand to serve, and work/school related time constraints on many urban customers, than anything else. Short encounter constrained the time vendors have with customers to personalize their relationship or foster and build strong ties. However, it has its benefits. Previous research illustrates for instance that brief service encounters minimises the chance of service script interference, which often impedes mutual understanding (Price et al, 1995; Mano \& Oliver, 1993). Among street vendors, the short service encounters motivate vendors to be transaction specific, thereby minimising the chance of emotional dissonance (Aziz, 2008). Thus while street vendors locate their businesses in strategic areas often characterised by steady pedestrians and vehicular traffic flows in order to make themselves, in terms of proximity, easily accessible to consumers, such decisions meant that they had to also deal with the reality of a short time frame in which to give service to their customers, who are generally on-the-go.

However, service culture practices among street vendors distant from the city centre reflected extended or long service encounter interaction. Typical comments from these vendors reflected their experiences:

"...When a customer gets to my stall, I start by greeting them and then I serve) them... from there, I try to socialize with them (customers)... I also try to convince them to buy other things from me..." [Thato].

“...The first thing when a customer arrives, I ask them what services they want...The most important thing is to show a customer love; by love, I mean giving customers a smile, so they can see that this vendor is not in a fight (angry mood) and as customers they can be 'free' (and relax). I ask customers if service is according to what they want... I modify accordingly... I accompany my customers as they leave... I explain to them that this is where they can always find me if they need my services... I even offer my cell phone number so they can contact me..." [Gaone].

Observations of street vendors distant from the city centre revealed their service encounters were never transaction specific. In many of the interactions and through sentiments expressed in the encounters, the interface more resembles boundary opening transactions, which transcend commercial relationships. Boundary opening business transaction is nested within the framework of friendship, and is associated with empathy, collegiality, and active emotional involvement. Consequently, it provokes self-revelation. In this kind of transaction, the service provider is actively involved emotionally, and the encounter is characteristic of a relationship rather than a mere transaction (Price et al, 1995). Among the street vendors located outside the city centre, more time was spent in their interaction with customers. Their interaction with customers began from as early as when the customer draws near to the transaction point and carried on until the customer departed. This exchange provided a mutual platform in which respect and other social values associated with service were expressed. Significant amount of time and emotional energy gets invested in extended encounters, which many scholars argue support the long term growth of the enterprise since it is more likely to result in boundary opening transactions (Price et al., 1995; Hoffman \& Kelly, 2000; Mohr \& Bitner, 1991). 
In the Botswana context, extended service encounter feeds naturally into the socio-cultural psyche of Batswana. The 'oral tradition' is highly valued in Botswana. Thus, there is a tacit expectation that service encounters should transcend transaction communication boundaries. Of course, for practical reasons, this is not always feasible, which may result in tension. Traditionally, the encounter is expected to be unhurried, thereby giving time for discussion and the showing of courtesy (Brown, 2005). This suggests there is more time for the vendor and the customer to display their feelings and to develop friendship in the unhurried atmosphere. When the unhurried expectation is breached, it runs the risk of being interpreted as abrupt and disrespectful. The investment of time in service encounters is more aligned with national cultural expectations.

Courtesy practices and emotional labour: An overwhelming 'sentiment' this study heard throughout the interviews was, "...when customers get to my 'stall' I greet them, and after we exchange greetings I ask them how I may help...." Good manners and politeness were key features of street vendor service practices and culture. These humane cues were intertwined with others, including the show of respect, thank you practices, and responding promptly to customers due to strong competition. Street vendors expressed sentiments that conveyed authentic commitment to appreciating their customers:

"[The customers] buy with respect and I sell to them with respect..." [Ompatile].

"...I do not discriminate [against or between] customers; I treat all customers with respect [and] I know they too are helping me to survive... I never argue with customers; if they buy and later complain that an 'orange' is rotten, I just peacefully replace it... [Tabisa]

“...I say thank you... If I don't have what [my customer] want I refer them to my neighbouring vendors..." [Gao].

Consistent with expectation, especially among street vendors outside the city, courtesy manifested at different transition points during service encounters, notably at the point of arrival of customers, during service request, and at departure.

Courteousness helped to build alliance and friendship network. Street vendors in both the city centre and in areas away from the city showed courtesy to customers, not just for its own sake but also to leverage it as a resource. It contributed to the maintenance of their customer base. Furthermore, through the 'humane service culture' treatment they experience, existing customers' word-of-mouth diffusion contributed to the attraction of new customers. Thus, inflows of customers form network of clients, based on acquaintances, and the friends in the network were leveraged at times to build and further expand the customer base by attracting new ones. One participant who lived the experience, remarked, “...We rely on our regular customers to tell their friends, and friend's friend, about us... that is why we try to please our customers" [Stella].

Courtesy was a significant part of street vendors' emotional labour. Hochschild (1983) defines emotional labour as managed feelings; the use of one's emotional energy to enhance the emotional state of others. Street vendors had to not just deliver a functional benefit, as in the case of vendor Tabisa who replaced a 'spoilt orange' to minimise complaint, but also had to communicate emotional benefits and be a 'friend'. Street vendors spoke about service practices where they loan their regular customers goods because the customers had no hard cash:

“...If you want to retain your own customers, you must understand that they don't always have money; some are working... when they are cash stranded at mid-month, they come and they say they don't have money... you just have to assist... you know they will pay month end; you must still ensure they are satisfied even when they come without money...." [Vasco].

Previous research confirms that service providers do offer customers emotional benefits (Noone et al, 2009; Arnould \& Price, 1993). For street vendors, it included trust, empathy, and feelings of cooperation. Like in Vasco's case, several examples where customers had desires for emotional benefits were mentioned during the interviews.

Street vendors made themselves both a focus of positive affect, “...I keep loyal customers by selling to them on credit, giving them time to pay on their own without rushing them...", and a channel of positive affect for their customers, "...Most of the time the customers applaud me, saying although this person's business is not blooming, it's their first time to see a street vendor who can just offer you sweets for free when you buy from her...." These practices and values collectively shaped how street vendors do things in their context.

Giving extras: Vendor-customer service encounter was characterised by a culture of giving extras. Extras included two aspects, “...give customers something more...", and "... attention; going the extra mile or out of the way." The whole theme of 'extras' was captured by Mipello:

"I satisfy customers...when you see that the customers are happy with your service you give them a few extra 
pieces for free... [it] attracts them to come buy from you next time.” [Mipello]

Neo goes the extra mile, “...I take time with my customers and give them attention; when a customer buys, you must show interest and kindness, and if you do not have what he/she wants, you have to show him/her where he/she can get it... that is what I do." The extras for Gaone were simply that, "...New customers expect me to start our conversations by making small jokes so that they can leave my stall happy" [with a smile].

Extras transcend a transaction-specific exchange, to include the sharing of benefits neither anticipated nor paid for. The provision of extras suggests the service relationship had a feeling of a friendship than commercial exchange (Noone et al, 2009), and the interaction was more boundary opening than closed (Price et al, 1995).

Formation of network with fellow vendors: The service culture practices among street vendors extended beyond interactions with clients. It involved exchange with fellow street vendors, at a more macro, or group, level. In the personal interview data, street vendors mentioned cleavages in inter-vendor networking and cooperation that they shared in "...to survive" the streets. In the words of one participant whose sentiment was typical, "...cooperating reminds us here on the street that all we have is each other". The personal interviews and instances in the personal observations show how street vendors, regardless of workplace location, orchestrated a system of cooperation and networking among fellow vendors for a variety of reasons. Vendors networked and cooperated to promote a culture of information sharing. One vendor said "...Yes, we network with others [street vendors] around... it is how we get to know there is a business promotion somewhere" [Patience].

The need to always satisfy customers, while faced with unreliability of material, human and financial resources, also provoked cooperation. Muiruri (2010) and others (Atholang, 2012; ILO 2002) assert that most street enterprises operate with limited resources, with the business often run by a single vendor or a family, with no employees. The ILO (2002) illustrates various constraints that street vendors faced, including lack of credit and insecurity. The system of cooperation and networking with each other appears a response to constraints that they faced as street vendors. The vendors' recognition of limitations which reinforced their belief in building strong network and function as community is reflected clearly in the following sentiment of one vendor:

"...We have to help each other...Sometimes, in the middle of serving a customer, the electricity might go down, or the generators might run out of power... you are then faced with a bad situation as the customer is still there... so we have to 'run' to the next vendor to borrow equipment, or to use their stall, to finish serving the customer, because you want to satisfy the customer" [Lockie remarked].

The complexity of the solidarity is illustrated in Veronica sentiments, which highlighted the practice of 'motsello' - a national cultural custom - in street enterprise practice. She said, "...Each week we each contribute a small amount of money in order to support each other to buy more merchandise...." Cooperation also manifested through referral of customers to other neighbouring vendors, as vendors repeatedly explained, "...if I do not have something [stock], I refer customers to my neighbours [other vendors]". It was also practised to maintain stability and peace among vendors operating within close proximity: "...When one [a vendor] is not present at his/her stall, you can sell their stuff on their behalf... We behave like we are family although we just met here". In other words, as another vendor explained, "...if I go to the toilet and a customer comes to my stall, she [the neighbouring vendor] would come to sell the customer at my stall and give me the money when I come back, instead of taking the customer". The pooling and sharing of resources represents the high point in the networking culture among street vendors. The 'motsello' arrangement, borrowed from the national culture, is demonstration of two things: (a) street vendors' inventiveness in overcoming the constraint of lack of access to credit, and (b) the penetration of national culture into business culture (Hofstede \& Hofstede, 2005).

There is a strong sense of community and collectivism that emanated from the engagement. This was most notable among street vendors who operated in the city and town. In these locations, vendor-to-vendor proximity was generally close. Proximity may explain the strong sense of community and collectivism. But it is also an outgrowth of the national culture that prevails in Botswana. One of the features of the community is that there are agreed treatments for deviant vendors. One vendor explained, “...Anyone here who do not satisfy customers well or who 'throw away' a customer, i.e., mistreat them, is rebuked. When a customer comes to my stall, I treat him/her better." In all of these actions, there seemed a tacit effort to protect a 'brand or image' as community of vendors. The action suggests the existence of unwritten expectations of members in the community. In other words, norms of behaviours appeared inherent among the group. Both the indication of the sense of community and norms of behaviours are consistent with group culture development (Li \& Karakowsky, 2001) and the communication of empathic feelings due to proxemic intimacy (Price et al, 1995).

But let us not forget that street vendors are in business, where essentially a neighbouring vendor is a competitor. The existence of a spirit of community and collectivism suggests street vendors are not driven by competition, 
but more a concern to, as one vendor puts it, "...satisfy the customers". It may be for this reason that referring a client to their neighbour, who is a competitor, was a relatively easy practice among vendors. In this sense, street vending enterprises are unique, compared to formal organisations where referral practise, in discretely operated formal business settings, is rare, at least in Botswana.

\subsection{Service Culture Practices and Values in the Physical Environment}

Concerns about sanitation: Boseo et al (2011) illustrate ways in which street vendors design customer experiences through the use of mechanical clues, including the use of unique carts to display their products. Bonnin (2006) maintains that the physical environment where service is delivered contributes to the overall service culture. Street vendors' recognition of the contribution that the physical setting of their business makes to customer service experience is reflected in the following sentiments:

"They [the customers] judge you from the way you present yourself and keep the place [the workplace]... as a result, I have to make sure the place is presentable; by this I mean that the place is fit-to-be seen and is clean because people [the customers] will just past you if you don't tidy up the place..." [Gao].

All the vendors observed made it their responsibility to sweep, dust and clean their vending facility and equipment and the areas surrounding their vending site before they begin trading and after they finish: “...In our environment everyone has to provide a rubbish bin for their customers, and we must clean our selling area every evening and empty the rubbish bin" [Amo]. Sanitation was foremost in their mind because inattention to it can prove costly, as Gao observed, "...[The customers] will just past you [the vendor]...." Reports in previous research (Acho-Chi, 2002; Walsh, 2010) of unsanitary tendency among street vendors are not supported in this research, which may be a sign of evolution towards maturity of the sector.

Orchestrate the physical space: The vendors operated from permanent/fixed stall (kiosk), temporary stall/contrivance, and portable devices (e.g., vehicles; mobile cart). The temporary architectural arrangement gave street vendors limited flexibility. But through careful orchestration, they designed the physical environment to shape customer experiences. Street vendors who operated from temporary facilities mounted shades to shield customers from direct contact with sunlight. Those in temporary and permanent structures enhanced their space with decorations and arranged their products for self-service. Those vendors who offered cooked food services provided chairs and tables to customers to dine, and had menu boards mounted to communicate the meals for the day. They also had a 'host' who 'welcomed' customers, and guided them through the meal menu, and cleans up after the customers have eaten.

The evidence of the present research supports previous studies which reported that street vendors' care about and act to enhance their 'immediate' service environment (Boseo et al, 2011; Terraviva, 2006). The practice to orchestrate the physical space through mechanical clues (Boseo et al, 2011) is a service culture that influences customers to think and experience the vending service in unique ways (Salzmann, 2007). This outcome is not unique to this study. Interestingly, although street vendors' action is in their business interest, it is not immediately clear whether their sanitation practices within the business extend to a wider concern for the environment or related corporate social responsibility issues. Again, this is hardly likely to be the case as street vendors have been accused of contributing to ecological stress (Dioup, 1992; Acho-Chi, 2002).

\section{Further Discussion and Conclusion}

The paper began by highlighting a neglected dimension related to service culture among street vendors in the informal business literature. The basic characteristics of the service culture practices and values among vendors in street enterprises were investigated. The analysis illustrates that street vendors consciously cultivated and sustained particular service cultures in their enterprises. The evidence revealed that service cultures were consciously cultivated and sustained not only in the service encounter interactions with customers but also in relation to the service environment.

Service encounters, which depict the interactions between the service provider and service recipient, comprised three components: duration of the encounter, affective contents of the encounter and proximity between those in the encounter. Service culture varied along these dimensions depending on whether the vendors operated their business within the city centre or in areas distant from the city centre. Service cultures were expressed in the physical environment of street enterprise through mechanic clues. The practical and theoretical significance of these findings are now discussed.

A major achievement of investigating service culture manifestations in street enterprise is demonstrating that service culture develops, and is part of, the informal street vending business contexts. Among street vendors, service culture manifested in various ways in practice during the service encounter as well as in the business 
environment. Eight distinct service culture practices manifested, among which were (a) courtesy to customers; (b) responsiveness and attention giving to customers; (c) investing time in relationship or extended encounter practices (especially among vendors outside urban centres); (d) location of business close to customers; (e) rewarding of loyalty through giving of extras; (f) valued empathy and offering of emotional benefits; (g) environment health and sanitation practices; and $(\mathrm{h})$ orchestration of the physical environment. The service culture practices encompassed not just rituals but also symbols (Hofstede \& Hofstede, 2005). But there was no direct reference to heroes; i.e., vendors, past or present, real or fictitious, who possess idealised characteristics. This may be a result of the relative history of the group's co-existence.

Nevertheless, the most visible demonstration of service culture was behaviour and artefact, which is consistent with Schein (2009) as well as Hofstede and Hofstede (2005) theorisation of culture. Most of the service culture practices reflect practices that occur during the service encounter, or in the 'moment of truth' (Price, Arnould \& Tierney, 1995); this may reflect vendors' awareness of the vital role they play in communicating the culture of their services to customers and the personal mechanisms, such as attitudes and appearance, necessary to convey such cultures. Street vendors may have developed this awareness through social cognitive processes of learning and mass communication (Bandura, 2001).

Although service values are held unconsciously, and are not observable directly, BCL (2013) stresses that they may be inferred from human actions under different circumstances. Our study also found that street vendors held strong service values. Among these were collectivism, cooperation, trust, empathy, patience, friendship and group harmony. Service practices provided sources from which many of these values have been inferred. For example, the strategy 'motsello' used to mitigate constraint to credit is based on principles of cooperation and friendship. 'Giving of extras' suggested an intrinsic thrust for sharing, empathy, and/or driven by the Biblical belief that 'giving is preparation to receive'. Evidently, and unsurprisingly, street vendors' service culture values in Botswana naturally reflect the history of the country and its people, as well as the general normative rules for behaviour. In Botswana, as elsewhere in Africa, collectivism is a national culture value (Hofstede \& Hofstede, 2005). In collectivist cultural milieu, group protection is stressed over individualism, which makes it unsurprising that values linked to community, harmony, cooperation and friendship emerged. The existence of different levels of depth of service culture conforms to the general theorization of depth of culture (Hofstede \& Hofstede, 2005).

Service culture developed, and was as much a part of, the informal street vending business contexts, as it is part of formal business contexts. In the formal business domain, service culture has been conceptualised and illustrated in ways associated with positive outcomes for both the organisations and their customers (Liao \& Chuang 2007; Lytle \& Timmerman, 2006). This view leads scholars such as Ostrom et al, (2010) to conclude that service culture is inherently fundamental in the process of value creation for both service organisations and their customers. Previously, none of these positive outcomes and theorization of service culture have been linked to the informal business context. The current research illustrated that street vendors actively pursued the building of service culture in their business in terms of the way they transact and interact with customers, network with fellow vendors, and orchestrate their service environment. Several factors were already known to influence the kind of culture developed around street vending in developing societies (e.g., Renaut, 2004; Jimu, 2004; Muiruri, 2010; DR1, 2007) but it was not yet known that service culture which aims to create value for both vendors and their customers was among them.

The existence of service values and practices and the emphasis placed on various aspects of these suggest service culture was esteemed as a resource in street enterprises (Yang, 2008). However, the way service culture is used served different purposes, compared to how it has been theorised for use as a resource in formal enterprise context. For instance, Yang 2008) contends that as a valuable and unique resource in organisation, service culture serves to give a business competitive advantages over its rivals. As fiercely competitive as street vending business can be (DR1, 2007), in this study the service culture has not developed in ways associated with competition and exploitation. To the contrary, it evolved in ways associated with cooperation, inter-business networking, and friendship. Service culture as their resource was directed at community building and intergroup support. The areas of agreement in the service culture among vendors in the different locations perhaps reflect deep-seated assumptions in Botswana about the goodness of human nature, coupled with perhaps the limited exposure to exogenous forces, and the resistance of the indigenous culture to the effects of exogenous community, family and economic practices. In Botswana, as elsewhere, people have access to differing resources depending on their socio-economic status, gender, or even place of residence (see Brown, 2005) and these constraints on vendors who normally are the marginalised may contribute to the outcomes.

Street enterprise is clearly couched in an informal socialisation. Unlike formal organisation, business practices in 
street enterprise are not guided by formal instruments such as policies, procedures, and structures. However, in line with Klein and Kozlowski's (2000) multi-level theory, the service culture that emerged among vendors is one which evolved as a bottom-up, as opposed to a top-up, process. Bottom-up processes begin at the individual level, and through dynamic interactions and social learning, the transfer of culture occurs and gains stable properties overtime. The fact that the street vendors identified with a common set of core values and related to more or less common normative behaviours (see Figure 1) suggests that the service culture was shared and stable.

A model of the service culture is shown in Figure 1. These represent components of service culture among street vendors. The service culture of street vendors is manifested through courtesy behaviours and through values such as collectivism. The service culture model needs to be tested, but it appears, for example, that it is beneficial for increasing a market and customer-centric orientation for the vendors.

\section{ELEMENTS OF SERVICE CULTURE IN STREET ENTERPRISE}

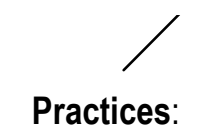

Humane and mechanical
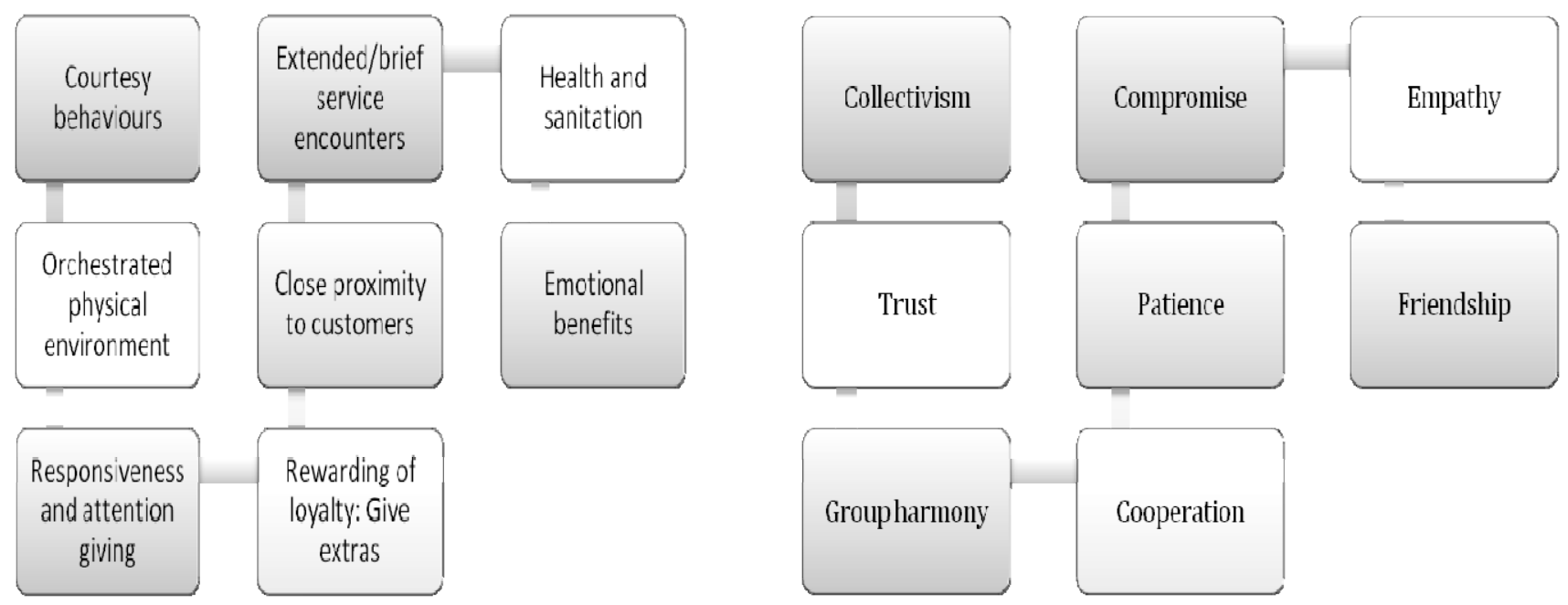

Figure 1. Model of service culture among street vendors

\section{References}

Acho-Chi, C. (2002). The mobile street food service practice in the urban economy of Kumba, Cameroon. Singapore Journal of Tropical Geography, 23(2), 131-148. http://dx.doi.org/10.1111/1467-9493.00122.

Atholang, T. (2012). Accounting practices used by female headed family managed informal businesses in Gaborone and Tlokweng, Botswana. Unpublished Bachelor of Arts Degree Dissertation. Gaborone: University of Derby and Botswana Accountancy College.

Aziz, Y. (2008). The effects of emotional dissonance and employee's empowerment on service quality and customer satisfaction perception: Customer level analysis. International Journal of Economics and Management, 2(2), 237-258.

Bandura, A. (2001). Social cognitive theory: An agentic perspective. Annual Review of Psychology, 52, 1-26. http://dx.doi.org/10.1146/annurev.psych.52.1.1

BCL. (2013). What are some examples of personal values? Online. Retrieved from https://answers.yahoo.com/question/index?qid=20090902202646AABBcJD

Bonnin, G. (2006). Physical environment and service experience: An appropriation model. Journal of Services Research, 6, 45-58. 
Boseo, M., Lee, S., Olson, E., \& Severt, D. (2011). Delivering Service To-Go: A Case Study on Street Vendor Operators in Central Florida.

Bowen, D. A., Schneider, B., \& Kim, S. S. (2000). Shaping service cultures through strategic human resource management. In T. A. Swartz \& D. Iacobucci (Eds.), Handbook of Services Marketing \& Management (pp. 439-454). Thousand Oaks, CA: Sage Publications.

Brown, B. (2005). The incorporation of poverty into adult identity overtime: implications for adult education. International Journal of Lifelong Education, 24(5), 393-404. http://dx.doi.org/10.1080/02601370500169731

Brown, B., \& Rammidi, G. (2012). Delivering service to go: Service culture aspects of street vending in Botswana. Paper presented at the 17th IVETA International Conference on Human Resource Development for Poverty Eradication. Mangochi, Malawi. Retrieved from http://www.voced.edu.au/txt/57901

Central Statistics Office. (2011). Informal Sector Survey for 2010-2011. Gaborone: Government Printers.

Central Statistics Office. (2012). Policy on Small, Medium and Micro Enterprises in Botswana. Gaborone: Government Printers.

Davis, R., Gautam, N., \& Bhat, R. (2012). Conceptualising service culture. Online. Retrieved from http://www.anzmac.org/conference/2011/.../Davis,\%20Robert\%20Paper\%20021.pdf

Deal T. E., \& Kennedy, A. A. (2000). Corporate Cultures: The Rites and Rituals of Corporate Life. Harmonds worth: Penguin Books.

DR1. (2007). Street Vendors: The DR's Mobile Supermarket. Online. Retrieved from www.dr1.com/articles/street_vendors.shtml

Erez, M., \& Gati, E. (2004). A dynamic, multi-level model of culture: From the micro level of the individual to the macro level of a global culture. Applied Psychology: An International Review, 53(4), 583-598. http://dx.doi.org/10.1111/j.1464-0597.2004.00190.x

Grönroos, C. (2007). Service Management and Marketing: Customer Management in Service Competition (3rd ed.). New York: John Wiley \& Sons.

Hoang, H., Hill, S., \& Lu, V. (2010). The Influence of Service Culture on Customer Service Quality: Local vs. Foreign Service Firms in Emerging Markets. Retrieved from http://www.anzmac2010.org/proceedings/pdf/anzmac10Final00502.pdf

Hochschild, A. (1983). The managed heart. Berkeley, CA: Universityof California Press.

Hoffman, D., \& Kelley, S. (2000). Perceived justice needs and recovery evaluation: A contingency approach. Europena Journal of Marketing, 34(3/4) 418:432.

Hofstede, G. (1984). Culture's consequences: International differences in work-related values. Newbury Park: Sage.

Hofstede, G., \& Hofstede, G. J. (2005). Cultures and organisations: Software of the mind (2nd ed.). New York: McGraw-Hill.

Hope, K. R. Sr. (1997). African political economy: Contemporary issues in development. Armonk, New York: Sharpe.

ILO. (2002). Decent work and the informal economy: Report VI. International Labour Conference, 90th Session, Geneva, Switzerland.

Inglehart, R., \& Baker, W. (2000). Modernisation, cultural change and the persistence of traditional values. American Sociological Review, 65, 19-51.

Jimu, I. (2004). An exploration of street vending's contribution towards Botswana's vision of prosperity for all by 2016. Pula: Botswana Journal of African Studies, 18(1), 19-30.

Johansson, E. (2013). Managing quality in a service context. Published Licentiate Thesis (thesis No. 15579). Linkoping University, Department of Management and Industrial Engineering. Linkoping: Linkoping University.

Kitayama, S. (2002). Cultural and basic psychological processes: Toward a system view of culture. Psychological Bulletin, 128, 89-96. http://dx.doi.org/10.1037/0033-2909.128.1.89

Klein, K., \& Kozlowski, S. (2000). Multilevel theory, research and methods in organisations. San Francisco, CA: 
Jossey-Bass.

Letebele, O. (2012). Strategic risk management practices in parastatal organisations and implications for corporate governance in Botswana: A case study. In B Brown (Ed.), The Book of Abstracts: BGAFR 2012. Gaborone: Botswana Accountancy College.

Li, J., \& Karakowsky, L. (2001). Do we see eye to eye? Implications of cultural differences for cross-cultural management research and practice. Journal of Psychology, 135, 501-517. http://dx.doi.org/10.1080/00223980109603715

Liao, H., \& Chuang, A. (2007). Examination of Transformational Leadership in Building Long-Term Service Relationships, Journal of Applied Psychology, 92(4), 1006-1019.

Lytle, R., \& Timmerman, E. (2006). Service Orientation and Performance: An Organizational perspective, Journal of Services Marketing, 20(2), 136-147. http://dx.doi.org/10.1108/08876040610657066

Lytle, R., Hom, P., \& Mokwa, M. (1998). A managerial measure of organizational service-orientation, Journal of Retailing, 74(4), 455-489. http://dx.doi.org/10.1016/S0022-4359(99)80104-3

Mano, H., \& Oliver, R. (1993). Assessing the dimensionality and structure of the consumption experience: Evaluation, feelings, and satisfaction. Journal of Consumer Research, 20, 451-466.

Martin, J. (2002). Organisational culture: Mapping the terrain. Stanford: SAGE.

Mohr, L., \& Bitner, M. (1991). Mutual understanding between customers and employees in service encounters. In Solomon, M., \& Holman, R. (Eds.), Advances in consumer research (vol. 18, pp. 611-617).

Muiruri, P. (2010). Women street vendors in Nairobi, Kenya: A situational and policy analysis within a human rights framework. Addis Abba: OSSREA.

Noone, B. M., Kimes, S. E., Mattila, A. M., \& Wirtz, J. (2009). Perceived service encounter pace and customer satisfaction: An empirical study of restaurant experiences. Journal of Service Management, 20(4), 380-403.

Ostrom, A., Bitner, M., Brown, S., Burkhard, K., Goul, M., \& Smith-Daniels, V. (2010). Moving forward and making a difference: Research priorities for the science of Service. Journal of Service Research, 13(1), $4-36$.

Poulin, M. (2010). Business ecology initiative and service-oriented solution: Intangible values of services. Online. Retrieved from http://www.ebizq.net/blogs/service_oriented/.../intangible_values_0f_services.php

Presidential Task Force. (1997). A long term vision for Botswana. Gaborone: Government Printers.

Price, L., Anould, E., \& Tierney, P. (1995). Going to extremes: Managing service encounters and assessing provider performance. The Journal of Marketing, 83-97.

Renaut, A. (2004). The informal economy: Women on the front line. Trade Union World Briefing (International Confederation of Free Trade Union, Brussels), 2, 1-3.

Russell, E. (2012). Five steps to excellent customer service. Retrieved from http://www.e-russell.com/images/Handout_13.5.pdf

Salzmann, Z. (2007). Language, culture, and society: An introduction to linguistic anthropology. San Francisco, CA: Westview Press.

Schein, E. (2001). Process consultation revisited: Lessons for managers and consultants. New York: Prentice Hall.

Schein, E. (2009). The corporate culture survival guide: New and revised edition. San Francisco, CA: Jossey-Bass.

Schneider, B., \& Bowen, D. (2009). Modelling the human side of service delivery. Service Science, 1, 154-168.

Siehl, C., Bowen, D., \& Pearson, C. (1992). Service encounters as rites of integration: An information processing model. Organisation Science, 3, 537-555.

Terraviva. (2006). The informal economy: Street vending in Asia. Retrieved from http://www.ilo.org/wcmsp5/groups/public/wcms_bk_pb_117_em.pdf

Vargo, S., \& Lusch, R. (2008). From goods to service(s): Divergences and convergences of logics. Industrial Marketing Management, 37(2), 254-259.

Vella, P., Gountas, J., \& Walker, R. (2009). Employee perspectives of service quality in the supermarket sector. 
Journal of Service Marketing, 23(6), 407-421. http://dx.doo.org/10.1108/08876040910985870

Walsh, J. (2010). Street vendors and the dynamics of the informal economy: Evidence from Vung Tau, Vietnam. Asian Social Science, 6(11), 159-166.

Yang, Y. (2008). The roles of human resources, information technology, and marketing knowledge capabilities in performance: An extension of the resource-based theory perspective. Social Behaviour and Personality: An International Journal, 36(9), 1269-1282. http://dx.doi.org/10.2224/sbp.2008.36.9.1269

\section{Copyrights}

Copyright for this article is retained by the author(s), with first publication rights granted to the journal.

This is an open-access article distributed under the terms and conditions of the Creative Commons Attribution license (http://creativecommons.org/licenses/by/3.0/). 